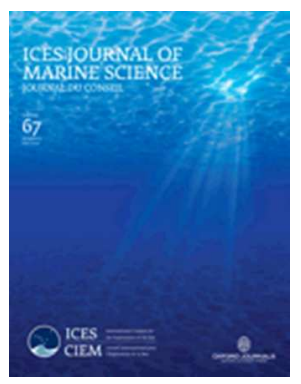

\title{
A review of the influence of marine habitat classification schemes on mapping studies: inherent assumptions, influence on end products and suggestions for future developments
}

\begin{tabular}{|r|l|}
\hline Journal: & ICES Journal of Marine Science \\
\hline Manuscript ID & Draft \\
\hline Manuscript Types: & Review Article \\
\hline Complete List of Authors: & $\begin{array}{l}\text { Strong, James; National Oceanography Centre, Marine Geoscience } \\
\text { Mitchell, Annika; Agri-Food and Biosciences Institute } \\
\text { Lillis, Helen; JNCC Support Co } \\
\text { Galparsoro, Ibon } \\
\text { Pesch, Roland; BioConsult Schuchardt \& Scholle Gbr } \\
\text { Bildstein, Tim; BioConsult Schuchardt \& Scholle Gbr }\end{array}$ \\
\hline Keyword: & Marine habitat mapping, habitat classification, classification schemes \\
\hline &
\end{tabular}


1 A review of the influence of marine habitat classification schemes on mapping studies: inherent assumptions, influence on end products and suggestions for future developments

\section{4}

5 James Asa Strong ${ }^{1}$, Annika Clements ${ }^{2}$, Helen Lillis ${ }^{3}$, Ibon Galparsoro ${ }^{4}$, Tim Bildstein ${ }^{5}$, $6 \quad$ Roland Pesch ${ }^{5}$

\section{$7 \quad$ Affiliations}

81 National Oceanography Centre, European Way, Southampton, SO14 3ZH, UK.

$9 \quad$ Corresponding author. Email: james.strong@noc.ac.uk

102 Fisheries and Aquatic Ecosystems Branch, Agri-Food and Biosciences Institute, 18a

11 Newforge Lane, Belfast, BT9 5PX, UK

123 Joint Nature Conservation Committee, Monkstone House, City Road, Peterborough PE1

13 1JY, UK

144 AZTI-Tecnalia, Marine Research Division, Herrera Kaia Portualdea z/g, 20110 Pasaia, 15 Spain

165 BioConsult Schuchardt \& Scholle Gbr, Reeder-Bischoff-Str. 54, 28757 Bremen, Germany 


\section{Abstract}

20 The production of marine habitat maps typically relies on the use of Habitat Classification 21 Schemes (HCSs). The choice of which HCS to use for a mapping study is often related to 22 familiarity, established practice, and national desires. Despite a superficial similarity, HCS

23 differ greatly across six key properties, namely, purpose, environmental and ecological scope, 24 spatial scale, thematic resolution, structure and compatibility with mapping techniques. These 25 properties impart specific strengths and weaknesses for each HCS, which are subsequently 26 transferred to the habitat maps applying these schemes. This review has examined seven 27 common HCSs, over the six properties, to understand their influence on marine habitat 28 mapping. Recommendations are provided for improving HCSs for marine habitat mapping as 29 well as for enhanced the working practices of mappers using habitat classification. It is hoped 30 that implementation of these recommendations will lead to greater certainty and usage within 31 mapping studies and more consistency between studies and adjoining maps. A review of six 32 common HCSs has been conducted to highlight these issues, and to raise awareness of how 33 these properties and assumptions are transferred into marine habitat maps. In addition, how 34 mappers use HCSs also introduces additional uncertainties and biases into the final maps.

\section{Keywords}

36 Marine habitat mapping; habitat classification scheme; 


\section{1. Introduction}

40 The pressing need for seabed inventory mapping, marine spatial planning, spatial estimates of 41 anthropogenic impacts (as required by the Marine Strategy Framework Directive (Council 42 Directive 2008/56/EC)) and the designation of seabed conservation features (as required by 43 the Habitats Directive 92/43/EEC) has made the habitat map an indispensable item within 44 marine management and research. The production, and ultimate presentation, of marine 45 habitat maps typically rely on the use of a habitat classification scheme (HCS). Within 46 mapping, HCSs categorise environmental and biological information (e.g., depth, 47 topography, substratum, hydrodynamic energy, community composition) into distinct habitat 48 classes. Each class is assumed to be associated with a distinctive abiotic condition and 49 identifiable biological community, and therefore attempts to produce environmentally or 50 ecologically meaningful units.

51 Habitat classification is an integral part of habitat map production, and as such, the HCS has a 52 significant influence on how mapping information is: (i) interpreted during map production; 53 (ii) displayed within the map; and (iii) interpreted by the end user. This review aims to 54 examine explicitly how HCSs influence the production of marine habitat maps. A wider 55 discussion will follow on what improvements can be made to HCSs, and how mappers should 56 use these HCSs, to provide more consistent, accurate and useful products for end users. The 57 specific objectives of this review are:

58 1. Introduce the principles of habitat classification for marine mapping;

59 2. Describe the properties common to most HCS;

60 3. Examine the variation in these common properties for seven, established HCSs, $61 \quad$ used for benthic habitat mapping; 
4. Assess the influence of variations within these common properties on the production and representations of marine habitat maps;

5. Make recommendations for the development of HCSs in habitat mapping; and

6. Recommend best practice for marine habitat mappers when using HCSs.

66

\section{2. Use of habitat classification schemes in marine mapping}

68 Although HCSs are developed to support all sorts of environmental work, few activities are 69 as intimately linked to the use of HCSs as habitat mapping. Many HCSs have been developed 70 specifically for use in mapping studies, e.g., Potential Habitat Characterization Scheme 71 (PHCS, Greene et al. 2005, 2007). This section introduces HCSs, as well as how and why 72 they are incorporated into marine habitat mapping. The influence that HCSs have on habitat 73 maps is also introduced, before being discussed in more detail at the end of the review.

\subsection{Habitat classification schemes}

Robinson and Levings (1995) defined a HCS as a set of instructions that identify, delimit and 77 describe the habitats of distinct biological assemblages (communities or single species). The 78 primary purposes of HCSs, summarised from Galparsoro et al. (2012) and Robinson and 79 Levings (1995), are to:

80 - provide a structured framework for the efficient classification of habitats;

81 provide common and easily understood concepts and language for the description of 82 habitats;

83 - hold information in a relational structure that allows for the interrogation of 84 information based on parameters collected by common survey methods; 
- describe and standardise the physical, chemical and biological parameters that define habitat classes; and

- regulate the spatial and thematic scales and thresholds used for habitat classification, and thereby standardise the classification of habitats within and between studies.

The use of a HCS benefits marine habitat mapping in several ways. Most importantly, the HCS provides a structured framework for the integration of environmental and biological information (which have different spatial scales, units, and formats) into one, integrated product, via ecologically meaningful decision points along the classification pathway. Ultimately, HCSs facilitate the segmentation of discrete (e.g., categorical data such as substratum) and continuous variables into ecologically relevant spatial units.

\subsection{The influence of habitat classification schemes on the outputs of habitat mapping}

Although the benefits associated with the consistent classification of habitats during mapping are great, it must also be recognised that the use of a HCS also imposes certain constraints and limitations, which are inherent within the fundamental concepts of habitat classification. For example, many HCSs assume that individual habitats are discrete classes. When used in mapping, these classes form mutually exclusive patches when presented spatially, and therefore fail to capture the natural continuities (biocoenoses) and environmental gradients (ecotones) that perhaps better reflect the natural configuration and gradients between different habitat types.

The structure of an HCS has a marked effect on the production process for a habitat map, through dictating when different types of information are relevant during the classification pathway. The structure can, therefore, modify the relative importance of physical, chemical 
109 and biological variables in determining the final classification for a unit of habitat. The

110 physical information is typically associated with the upper levels of the hierarchy and can

111 sometimes be assigned based on existing, coarse-resolution data such as from hydrodynamic

112 models and digital elevation models. Lower levels of classification (biotopes, communities

113 and single-species distribution) often require biological data and are often applied at a more

114 local scale. Due to insufficient biological data, or because it is not relevant for the specific

115 scheme or level of classification, some HCSs are based purely on physical and environmental

116 features of the seafloor environment, which are used as a proxy for habitats, on the

117 assumption that there may be a correlation between the non-biological features and biological

118 communities (Brown et al., 2011; Huang et al., 2011). Such assumptions are the basis for the

119 use of distribution modelling techniques by employing full spatial coverage data of

120 environmental variables to predict benthic spatial distribution patterns during the map

121 production (Reiss et al., 2014).

122 Although it is a sensible aspiration that a single classification scheme is used for all marine

123 habitat maps, multiple schemes have arisen to cater for the different applications, e.g.,

124 biological conservation, landscape ecology, environmental monitoring, marine spatial

125 planning, fisheries management, and geomorphological descriptions, etc. The presence of

126 several HCSs also reflects the fundamental difficulty of dividing natural continuities

127 (biocoenoses) and environmental gradients (ecotones), into discrete and meaningful classes

128 (McDougall et al., 2007). Furthermore, the number of HCSs is further inflated as individual

129 schemes cater for specific biogeographic areas. Lund and Wibur (2007) and Greene et al.

130 (2008) summarised 14 marine HCSs developed for North America and Europe alone.

131 Interestingly, schemes differ substantially even though (i) the main physico-chemical

132 variables that are known to define habitats are well-established, (ii) the majority of marine

133 mapping studies record the same parameters and (iii) the predominantly physical nature of 
134 the majority of the classifications. The use of different HCSs for mapping can significantly

135 influence the spatial representation of habitats in the final maps, which in turn can hinder the 136 merging of adjoining maps as well as alter management outcomes based on these maps.

137

138

139

140

\subsection{Variation and influence associated with six common properties of marine habitat classification schemes}

An examination of the HCS suggests that they differ according to six properties, namely: (i) purpose of a HCS; (ii) environmental and ecological scope of a HCS; (iii) spatial scale covered by a HCS; (iv) thematic resolution covered by a HCS; (v) structure of a HCS; and (vi) compatibility of a HCS for habitat mapping. Variation in each property can influence the production, and representation, of a marine habitat map. The following section will: (i) introduce each property; (ii) examine seven common HCSs to highlight the variation within each property (these schemes are introduced in Table 1); and (iii) summarise the influence of variation, within each property, on habitat map production.

\subsubsection{The purpose of a habitat classification scheme}

A number of HCSs have been constructed for differing but specific purposes. For example, some schemes are designed to address the delineation of fisheries habitats, while others specifically include habitats of conservation importance. Most schemes are more generic classifications, which are more suitable for inventory mapping. The purpose of a HCS dictates the emphasis for separation between classes, and therefore the way in which observed variables are partitioned within the scheme. This structuring is reproduced within a habitat map when a specific HCS is used. 
157 The majority of HCSs are generalist, descriptive schemes that potentially offer the greatest

158 utility to the largest number of users. Maps produced using these schemes are most likely to 159 be centrally collated and widely distributed. For instance, European policies, including the 160 Habitats Directive (92/43/EEC), the Marine Strategy Framework Directive (MSFD; 161 2008/56/EC), the Infrastructure for Spatial Information in the European Community 162 (INSPIRE; 2007/2/EC), and the Maritime Spatial Planning (Directive 2014/89/EU), aimed at 163 marine mapping, assessment and reporting are increasingly using EUNIS and HELCOM 164 Underwater Biotopes (HUB) (within the Baltic Sea) habitat categories and respective codes 165 so as to guarantee a common shared path and technical terminology between Member States 166 (Vasquez et al., 2015).

167 The Australian National Intertidal/Subtidal Benthic (NISB) scheme (Mount et al., 2007) and 168 the Classification of Sublittoral Habitats (CSH) scheme (Valentine et al., 2005) are also broad 169 enough to allow full coverage mapping and use for the environmental management of 170 seafloor habitats (although NISB primarily focused on managing climate change related 171 issues), as well as specifically providing a foundation for scientific research.

172 The primary purpose of Coastal and Marine Ecological Classification Standard (CMECS) is 173 to be a national standard for the classification of habitats that ensures the consistency of state, 174 national and international outputs (Madden et al., 2005). Unlike other schemes, CMECS is 175 claimed to be relatively multipurpose in that it also caters for (i) fisheries management; (ii) 176 the identification and administration of marine protected areas (Madden et al., 2005); and (iii) 177 ecosystem-based management of marine resources. By contrast, the Potential Habitat 178 Characterization Scheme (PHCS: Greene et al. 1999, 2005, 2007) has a clear geological 179 emphasis, which is thought to provide a better basis for fisheries management, i.e., the 
180 identification of Essential Fish Habitat. Consequently, this scheme has been adopted for the 181 contiguous western coast of the USA for rockfish habitat mapping (Greene et al., 2007).

182 Management purposes lie at the heart of the Hierarchical Framework of Marine Habitat 183 Classification for Ecosystem-Based Management (HFMHC: Guarinello et al., 2010), which 184 has been specifically designed for promoting ecosystem-based management (Guarinello et $185 a l ., 2010)$. The framework incorporates the central concepts of ecosystem-based management 186 - this ensures that the products of this HCS reflect the values and objectives of this style of 187 management. The HELCOM HUB scheme has also been designed to align with a strategic 188 plan to ensure ecosystem-based management (HELCOM Baltic Sea Action Plan) in the entire 189 Baltic Sea region (HELCOM, 2013).

191 The majority of HCS are generic, inventory schemes that have subsequently been adopted for 192 use in marine management. Several of the European systems were, however, designed 193 initially for the ready identification of habitats of conservation importance. Other schemes are 194 more specific, in either dealing with components of the habitat (e.g., ground fish), specific 195 management topics (e.g., climate change, fisheries, conservation, ecosystem-based 196 management). The purpose of an HCS will dictate the information that is required within the 197 classification and, ultimately, how this information is partitioned and presented within a map. 198 Most habitat mapping studies adopt just one HCS, and consequently limit the maps to a 199 specific set of purposes. This restricts both the breadth of the maps for other purposes and 200 how exhaustively the mapping data is used. It is likely that the greatest utility, accuracy, and 201 confidence for a purpose can be obtained from a map classified using a scheme dedicated for 202 that particular purpose. 
204 The scope of an HCS defines which (i) biogeographic region(s), (ii) biological realms (e.g., 205 pelagic/benthos), and (iii) type of habitats included (e.g., coastal area, estuaries or hard 206 substrata) are covered by the scheme. In some cases, a HCS will have been developed for a 207 specific biological component, study or geographic location, and the resulting habitat types 208 may not be applicable beyond that subject or area. In other cases, schemes have been 209 developed using broad-scale data or using thresholds in ecologically relevant variables 210 (Vasquez et al., 2015).

$211 \quad$ Variation in the scope of habitat classification shemes

212 The combined geographical scope of HELCOM HUB and the marine section of EUNIS is the 213 marine waters off the European mainland, including offshore islands, and the archipelagos of 214 the European Union Member States. Some regions are included in the scheme in principle, 215 although knowledge from these areas is more limited, and their habitats descriptions are 216 therefore poorly represented; e.g., the Black Sea and the Canary Islands. The HELCOM HUB 217 and EUNIS schemes cover the entire seabed from the intertidal zone into deeper, subtidal 218 areas (EUNIS also extends into the abyssal zone), as well as some broadscale pelagic 219 habitats. Both schemes are heavily biased towards parts of Europe that have been well220 studied and have existing HCSs (Galparsoro et al., 2012). Likewise, both the NISB and 221 CMECS schemes are also designed for a broad set of habitats yet within specific geographic 222 regions, i.e., NISB covers all of Australia's territorial waters between the high tide and out to 223 the limit of the photic zone (depth of $50-70 \mathrm{~m}$ ) and CMECS includes all estuarine, coastal 224 and marine waters under U.S. jurisdiction in North America. Although initially developed for 225 the Gulf of Maine region, the CSH scheme (Valentine et al., 2005) scheme is a generic 
226 classification and can, therefore, be applied to any continental shelf and shelf basin

227 environment globally (excluding some low-latitude environments).

228 Other classifications have an even broader geographical scope. The PHCS was initially 229 developed for use in specific deep-water habitats within North America (Greene et al., 1999, 230 2005, 2007). The PHCS has been expanded to include shallow water habitats, Arctic to 231 tropical regions, including Antarctica (Vietti et al., 2001) and estuaries (Greene et al., 232 2007b). The upper levels of the HFMHC (Guarinello et al., 2010) was designed, from the 233 beginning, to start with the global classification of large marine ecosystems (Sherman and 234 Alexander, 1986). Subsequent levels include distinct ecosystem units, e.g., estuary, and 235 broad, geological formations such as drowned river valley. The classification splits into three 236 and covers the water column, benthos, and human activity/impacts. The flexibility to add 237 user-defined classes at the lower levels of all three strands means the framework can be 238 applied in any geographic location and is not limited by the methods used to observe any of 239 the three classifiable components.

\section{Summarising the influence of habitat classification scope on habitat maps}

241 The sample of HCSs considered within this review span a range of habitats and geographical

242 regions. Some schemes are broad in their scope from design, whereas others have grown to 243 include new areas, such as the PHCS (Greene et al. 1999, 2005, 2007) and the CSH,

244 Valentine et al., 2005). Classes in locally calibrated classification schemes are more likely to 245 match the observations made in similar habitats or geographical areas. By contrast, classes 246 within broader, generic schemes are likely to have to generalise class descriptions, thereby 247 diminishing the ability of the scheme to reflect localised variation (reduced specificity) in 248 habitats. However, habitat maps generated with broad-scale HCSs are more likely to be 249 compatible with other maps and contribute to national and international mapping efforts. 
250 Furthermore, the output format and classes of maps using broad-scale HCSs will be familiar,

251 and hence more applicable, to more end-users that are already acquainted with the coding and 252 purpose of the selected HCS.

253

254

255

256

257

258

259

260

261

262

263

264

265

266

267

268

269

270

271

272

\subsubsection{The spatial scale covered by a habitat classification scheme}

The seabed can be characterised and classified at different spatial scales ranging from the fine-scale, local environment $(\sim 1-10$ s metres), with factors affecting individual organisms, to landscapes and large-scale ecosystems $(\sim 100-1000$ s metres $)$ where the substrates, terrain, and oceanographic settings influence biological communities and populations.

\section{Variation in the spatial scale between habitat classification schemes}

Progression through both the EUNIS and HELCOM HUB hierarchies results in finer thematic resolution as well as a finer spatial scale, e.g., a level 5 habitat is expected to cover a smaller area than its parent habitat at level 4. Helpfully, both schemes also provide an indication of the minimum spatial footprint for the finest units, e.g., as a working guide, biotope units extends over an area of at least $5 \mathrm{~m}$ x $5 \mathrm{~m}$, but can also cover many square kilometres, such as for extensive offshore sediment plains. For minor habitats, such as rockpools and overhangs on the shore, this 'minimum size' can be split into several discrete patches at a site. The NISB scheme may be applied to fairly fine scales, while the upper tiers of the classification hierarchy, which has a reduced number of habitat classes, may be applied to broader, regional scales. The NISB scheme is particularly helpful in that it defines a 'reference area' of $9 \mathrm{~m}^{2}$, for the assessment of habitat and biota dominance. Class modifiers applied to fine-scale features must be applied at the scale of the reference area as a minimum. This reference unit was deemed appropriate for a range of sensing techniques and a practical 
273 measure that can be easily made in the field with the current observation sensors and

274 methods, such as videography and diver.

275 To allow for the varying scales of map production and use, the PHCS (Greene et al. 2005, 276 2007), recognises and defines four spatial scales. The macro- and micro-habitats can be

277 nested within the smaller-scale mega- and meso-habitats. The appearance of specific habitat 278 scales can, therefore, be linked to the scale of observation, thereby aiding the production and 279 visual interpretation of the maps e.g. using dynamic segmentation methods such as those 280 detailed by Nasby-Lucas et al. (2002). The tiers associated with the HFMHC scheme 281 (Guarinello et al., 2010) are also associated with specific spatial scales, but no strict spatial 282 constraints are set for any level, thereby allowing any project to be fitted within the 283 framework. Equally, CMECS is designed to operate at multiple spatial scales and provides 284 the specificity needed for local-scale applications. Like the previous two schemes, each level 285 within CMECS is associated with a specific spatial scale, ranging from $10-1000 \mathrm{~km}^{2}$ at the 286 first 'regime' level, to $1-100 \mathrm{~m}^{2}$ at the final 'biotope' level. As such, CMECS allows the 287 aggregation and assessment of classified units across diverse systems at regional, national or 288 global scales without loss of utility at local levels. These scales are useful in guiding the Summarising the influence of habitat classification schemes scale on habitat maps

291 The consideration of scale is relevant for several aspects of habitat classification, map 292 production and usage. Firstly, the scale, and associated spatial resolution of a scheme 293 determines which physical or ecological features can be represented on a map and what level 294 of habitat heterogeneity can be captured. It is recognised by most mappers that many spatial 295 units of classified habitat are mixed classes or mosaics. For simplicity, spatial units are 296 typically labelled according to the dominant class and information regarding secondary 
297 habitats either removed or appended as a modifier. HCSs associated with finer spatial scales

298 reduce the need to generalise mosaicked habitats and thereby better reflect heterogeneity at 299 more scales. It should be noted that it is rarely stated within HCSs that units must be mutually 300 exclusive i.e., multiple habitat codes can be attributed with either a proportion or probability 301 and then allocated to a single, spatial unit.

302 Secondly, the scale of the HCS may also determine the type of mapping information, and 303 therefore mapping methodology, required for the classification. For example, deep-water 304 acoustic surveys may not have the required resolution for the identification of habitat classes 305 with small footprints, whereby requiring the use of Autonomous Underwater Vehicles 306 (AUVs)-mounted sonars for data collection. Furthermore, schemes that stipulate minimum 307 mappable units and area thresholds for habitat classes also benefit the mapper and reduce the 308 number of subjective decisions that might be needed during the production of maps. The final 309 issue is that the scale addressed by the HCS also defines the type of management supported 310 by the maps. For example, localized impact assessments will require maps with a sufficient 311 resolution for the accurate prediction of impact.

\subsubsection{The thematic resolution covered by a habitat classification scheme}

313 The thematic resolution specifies how fine the increments are between classes within a parent 314 habitat. For schemes with a high thematic resolution, one might expect a high number of 315 classes, each separated by relatively small differences in environmental or biological 316 variables. By contrast, low thematic resolution would entail a small number of coarser habitat 317 classes.

318 Variation in the thematic resolution between habitat classification schemes

319 The most detailed levels in the EUNIS and HELCOM HUB classification schemes are 320 predominantly defined by biotopes and therefore separates classes according to small, but 
321 significant, biological differences in otherwise similar habitats. In EUNIS, many of the

322 biotopes at levels 5 and 6 originated from statistical clustering analysis and expert 323 interpretation of data from diver surveys and intertidal surveys (rather than grab or remote 324 video) in the EC Life Nature-funded BioMar project (Connor et al. 1997). Equally, level 5 325 biotopes in the HELCOM HUB scheme were defined by analysing more than 50,000 data 326 observations (i.e., video data, diving observations, grab samples) using spatial and statistical 327 methods as well as expert judgment.

328 The PHCS (Greene et al. 2005, 2007), CSH (Valentine et al., 2005) and the NISB scheme 329 use modifiers to provide greater thematic resolution and flexibility for the finest classes 330 present. The PHCS uses single letter modifiers that describe specific aspects of geology, 331 biology, topography and seabed texture. These modifiers can be allocated to any of the six332 letter habitat codes used by the scheme. There is no limit to the number of modifiers that can 333 be attributed to each habitat code. Similarly, three themes within the CSH classification also 334 provides modifiers that allow the user to describe 'biological' 'habitat association and usage' 335 as well as short descriptors for 'community disturbance and recovery'.

336 Developing the use of modifiers further, the Hierarchical Framework of Marine Habitat 337 Classification for Ecosystem-Based Management (Guarinello et al., 2010) scheme permits 338 the use of user-generated classes (typically at the 'data analysis' level) and modifiers at most 339 of the levels within the classification, which therefore allows for any type and level of 340 thematic resolution. Units of information at the lowest levels of the framework can include a 341 variety of relevant information such as absolute values of abundance, dietary composition for 342 dominant species, rates for species-specific ecosystem functions and observed ranges for 343 important physico-chemical characteristics. 
345 For the majority of the schemes, the finest classes are resolved according to biological 346 characteristics of sessile benthic species. In some HCSs, more resolution is provided through 347 the use of class modifiers rather than distinct classes. Such information displayed with 348 classified habitats on the same map is likely to be valuable to a variety of map users. 349 However, modifiers that unduly extend the basic classification of a habitat (i.e. 'what it is') 350 are likely to complicate the habitat representation into maps, their interpretation by end users 351 and reduce comparability between maps.

352 The greatest level of thematic resolution differs substantially between HCSs. This is due to 353 either a shortage of information for the formation and validation of these most detailed 354 classes or that the overall purpose and scope of the HCS does not concern itself with detailed 355 biological information. Regardless of the HCS used, mappers must be aware of the level of 356 the classification that can be safely supported by the survey data, e.g., what level of 357 community classification can be supported by epibenthic video, and what the intended 358 purpose of their map will be. Equally, to improve the compatibility of maps, attempts should 359 be made not just to standardise the use of HCS (or suite of HCSs) for mapping but also to set 360 the level of classification within a scheme for a specific mapping technique (matched to a 361 specific purpose).

\subsubsection{The structure of a habitat classification scheme}

364 The structure of HCS can be either hierarchical or flat, as well as nested or un-nested (parallel 365 hierarchies). For hierarchical structures, the highest tiers typically separate observations into 366 coarse classes using broad physical and chemical variables. Lower tiers proceed to refine the 367 classification based on more localised, physico-chemical variables, as well as biological 
368 information on the composition of the communities present. Flat classification structures do

369 not nest classes under predefined physico-chemical pathways. As such, flat structures allow

370 the user to combine physico-chemical classes with independent biological classes - such

371 classifications may not be possible within hierarchical structures if the required biological

372 class is not nested within the observed physico-chemical pathway. The restrictive nesting of

373 classes within hierarchical structures is only a significant issue when the training data used to

374 develop the HCS was not reflective of habitat conditions apparent throughout the intended 375 area of application.

$376 \quad$ Variation in structure between habitat classification schemes

377 EUNIS, HELCOM HUB, and CMECS (substrate and biotic components only) are all 378 hierarchical schemes with six levels of marine classification. For example, the first two levels 379 of the CMECS scheme separate observations according to (i) salinity, geomorphology, and 380 depth, and then (ii) by substrate type or water mass characteristics - additional levels sort 381 observations by (iii) physical zones, (iv) macrohabitats (large and physically complex units 382 containing several habitats), (v) habitats defined by physical and energy characteristics and 383 finally, (vi) by characteristic biological composition. This structure is similar to both EUNIS 384 and HELCOM HUB. For both systems, the structure of the hierarchy assumes that classes at 385 the same level are mutually, and hence spatially, exclusive. Equally, specific communities 386 and biotopes in the lower levels of the hierarchy are nested under specific physical conditions 387 (defined by higher levels) and are not transferable between physical habitats. The NISB 388 scheme is also hierarchical but with fewer levels. At the higher levels of the hierarchy, the 389 NISB scheme assumes spatially exclusive habitats. The scheme uses 'decision rules' for 390 attributing habitat classes and for allocating geomorphic, biological and environmental modifiers. These decision rules allow simple, unambiguous interpretation of survey data and 
392 facilitating the objective and consistent assignment of habitat classes. The decision rules are 393 framed to be as sensor/method-independent as possible.

394 The PHCS is also hierarchical but has an un-nested structure. This scheme has separate 395 attribution pathways for the classification of small-scale (megahabitats and mesohabitats) and 396 large-scale (macrohabitats and microhabitats). The small-scale classification uses various 397 environmental parameters to provide increasingly finer thematic classes. The large-scale 398 pathway initially attributes the seafloor according to geological and coarse biological classes, 399 and then followed again by textural attributes. Similarly, the lower levels of the HFMHC 400 (Guarinello et al., 2010) scheme has three parallel (un-nested) 'benthic', 'water column' and 401 'human' hierarchies. The use of separate components within the framework avoids the 402 difficulty of generating a single hierarchy for fundamentally different domains and the 403 flexibility and structure of this framework allow for a broader storage of information. 404 However, the interaction of the three hierarchies generates a large number of unique habitat 405 classes.

406 The CSH (Valentine et al., 2005) scheme is quite different in structure to the other schemes 407 considered, as it is structured round eight, non-hierarchical seabed 'themes' as the major 408 subject elements of the classification. These themes are seabed topography, dynamics, 409 texture, grain size, roughness, fauna and flora, habitat association and usage, and habitat 410 recovery from disturbance. The themes all reside at the top level (i.e., are not hierarchical) 411 and are applied to the classification of each site. Below the themes, a sequence of more 412 hierarchical subclasses, categories, and attributes address habitat characteristics with 413 increasing detail. This scheme was developed to be used exclusively for mapping purposes. 414 As such, it was designed with a flexible structure to account for both data availability while 415 maintaining a framework that is considered the best method of representing the habitats on 
416 maps based on the classification. The classification can accommodate new classes,

417 subclasses, categories, and attributes, and it can easily be modified or expanded to address

418 habitats of other regions.

$419 \quad$ Summarising the influence of habitat classification scheme structure on habitat maps

420 Most of the HCSs adopt a hierarchical structure, with the initial levels typically referring to

421 broad-scale physical variables, biogeographic or domain regions. Classes within lower levels

422 are either nested under higher level classes or are open and unrestrained by the high-level

423 class. Hierarchical schemes allow habitats to be aggregated to a coarser level, thus allowing

424 comparisons to be made between different studies using the same scheme, even when

425 different levels of detailed information are available. These comparisons, however, are only

426 possible if the HSC is interpreted consistently, and rests upon a thorough understanding of

427 the scheme and how best to classify information using the scheme.

428 A nested structure will provide a smaller but more targeted number of possible classifications 429 - this is likely to benefit consistency and compatibility between studies. However, Galparsoro 430 et al. (2012) reported that for EUNIS, a nested hierarchy, some communities occur in 431 different main branches of the hierarchy due to their variations in associated depth or 432 sediment type, whereas in reality, they are very similar. Equally, some communities only 433 occur in a single branch of the hierarchy because they are mainly associated with certain 434 physical conditions; however, if the same community is observed with a different set of 435 physical conditions, then it would not fit precisely in the existing category. Schemes with an 436 open structure provide the user of the classification more flexibility to generate classes not 437 previously documented during the development of the classification. Open, un-nested 438 structures are perhaps best-suited for mapping in areas that may be poorly represented within 439 more trained and structured classifications. 
441 Although several HCS have been designed specifically for mapping studies, this was not the

442 intended purpose for all of the HCSs used in habitat mapping. As such, some of the decision 443 points or environmental and ecological parameters that structure HCSs may not be routinely 444 collected, or possible to observe, using the methods routinely deployed for marine habitat 445 mapping. As such, the ease with which an HCS can be applied to mapping data can vary. 446 HCSs that are designed specifically for mapping are more likely to be aligned to the 447 commonly collected variables and include quantitative thresholds or decision points 448 appropriate for these types of data and value ranges.

$449 \quad$ Variation in the compatibility of mapping techniques between habitat classification $450 \quad$ schemes

451 EUNIS has been used extensively for mapping and modelling (e.g., EUSeaMap, Vasquez et 452 al., 2015; Populus et al., 2017) efforts and have collectively produced a pan-European habitat 453 map for a coordinated approach to marine conservation, assessment of the status of marine 454 waters and spatial planning. Until now, HELCOM HUB has been applied in national case 455 studies only (e.g., Schiele et al. 2014, 2015). However, the use of the light penetration depth 456 as a major structural variable in the HELCOM HUB scheme means that additional 457 observations (not typically collected during marine habitat mapping) or external modelling 458 outputs must be combined with the mapped variables to generate a classification. The same 459 holds true for EUNIS regarding light availability and wave exposure at the seabed. The NISB 460 scheme is interesting in that it provides an umbrella scheme that can adopt and amalgamate 461 other classification schemes into its hierarchical system, i.e., the NISB scheme can be used to 462 translate existing local habitat maps into a single, aligned product (Hilbert et al., 2007). The 
463 flexibility of this scheme allows old maps and mapping data to be translated into new and 464 aligned products.

465 The EUNIS scheme has been criticised for incompatibilities between the information used to 466 define classes and that typically collected during a mapping survey. Levels 5 and 6 of the 467 hierarchy are based on data from a wide variety of sampling techniques; as a result, they 468 describe different aspects of seabed habitats. For example, some biotopes describe infaunal 469 communities, while others describe epifaunal communities. Robinson et al. (2009) argued 470 that some biotopes can only be identified if the method used during survey work is the same 471 as the method used to originally define that biotope. For example, the characteristic species 472 defining the level 5 biotope "Hesionura elongata and Microphthalmus similis with other 473 interstitial polychaetes in infralittoral mobile coarse sand" are tiny polychaetes that would be 474 grossly under-sampled using all but the finer meshes for sieving sediment. The $1 \mathrm{~mm}$ sieve 475 used as standard on offshore surveys would not retain meiofauna such as these polychaetes 476 (Parry, 2014).

477 The classes within the PHCS of Greene et al. $(1999,2005,2007)$ are mostly defined by their 478 geological character. As such, the scheme is well suited for the detection of habitats using 479 acoustic remote sensing and thereby increases the confidence in the resulting classification. 480 However, the biological classes are coarse, exclusively epifaunal and taxonomically distinct, 481 which is perhaps unreflective of the typical composition of many seafloor communities and 482 means that seafloor biota only have a fairly minor influence on the overall classification. The 483 CMECS scheme is designed to be compatible with a range of sampling methods, e.g., 484 cameras and certain acoustic devices can be used to identify the higher classification levels, 485 while traditional point sampling methods, such as sediment sampling using grabs, can be 486 used for the lower levels of classification. Equally, the sediment classes within CMECS are 
487 aligned to the Folk (1954) sediment classification, which is an established scheme in marine

488 habitat mapping. This differs from the EUNIS classification which is underpinned by a 489 'modified' (simplified) Folk classification.

491 The ease with which habitat mappers can integrate HCSs is based on the compatibility of the 492 scheme's classifying variables with survey outputs. For example, in the PHCS presented by 493 Greene et al. $(2005,2007)$ several of the classification attributes are generated specifically 494 from common acoustic parameters such as depth (for bathymetric zones, slope, and rugosity) 495 and backscatter (for hardness). Most of the geomorphological classes for other attributes are 496 easily identifiable from full coverage bathymetric surfaces. However, it is clear that the ease 497 and accuracy of classification also varies between habitat types. For example, it may be 498 relatively straightforward to distinguish rock from muddy habitat in multibeam echosounder 499 backscatter data, while there may be no clear boundary between coarse and mixed sediment. 500 At the more detailed levels, many of the differences in the communities cannot be 501 distinguished in acoustic data and therefore they are difficult to map.

502 Difficulties in finding an appropriate class can be further compounded when HCSs are biased 503 towards the habitats used in the initial development of the classification. For example, the 504 marine component of EUNIS is primarily based on the British-Irish BioMar scheme, which 505 was originally developed largely using UK near-shore data, primarily from grab sampling 506 and, to a lesser extent, diver surveys (Connor et al., 2004). This means that EUNIS is less 507 well-developed for offshore habitats, particularly those occurring on hard substrates. 508 Furthermore, EUNIS is arguably less well developed for interpretation of data from remote 509 video techniques which sample different parts of a biological community than divers or grab 510 samples, and at a different scale, therefore posing difficulties in matching the communities 
511 from video/photographic techniques to the statistically driven clusters from grab sample and

512 diver surveys. Similarly, certain classifications have been developed to use certain data types, 513 e.g., schemes developed for the interpretation of satellite imagery (e.g., Mumby and Harborne 514 1999), and may therefore not apply to data obtained from other sources.

\section{Recommendations for the use of marine habitat classification schemes in marine} mapping

518 This review will firstly summarise the most influential aspects of HCSs in marine habitat

519 mapping and consider how this influence can be accounted for, or reduced, in habitat 520 mapping. Some of the common limitations associated with the use of HCS in habitat mapping 521 are often propagated by how habitat mappers use HCSs rather than being issues implicit 522 within the schemes themselves - these issues are also discussed below and recommendations 523 are provided.

\section{Defining 'actual' and 'potential' habitats within mapping}

525 Many habitat maps present an unspecified mixture of 'realised' and 'potential' habitats when 526 using HCSs. For example, the upper classification levels of many HCSs divide areas by 527 geomorphology and rely on acoustic survey data to achieve this delineation. Continuous 528 bathymetric surfaces can, therefore, confirm the presence of large, physical features from 529 observations. Observations of biotopes are only provided by point (e.g., grab or photographic 530 still) or line (e.g., video transect) sampling during ground truthing. The continuous 531 distribution of the biotopes is then predicted using geo-spatial modelling or expert judgment, 532 meaning that the resulting distribution is an extrapolated product not fully supported by direct 533 observation (unless one is mapping a biogenic biotope with a detectable structure). The 534 predictor variables typically used to model the distribution of these biotopes also fail to 
535 represent influential biological processes such as competition, predation, and dispersal 536 (Brown et al., 2011). As such, one is modelling 'potential' habitat for that biotope, which 537 may or may not be occupied by the species constituting that biotope. The distinction between 538 features that are realised versus potential habitat is rarely explicitly expressed when 539 presenting mapped habitat classes. A lack of specificity may contribute to inaccurate 540 assessments of the confidence of habitat maps by end-users, uncertain assessments of extent, 541 and ambiguity about the relevant management action for sites and feature. It is therefore

542 recommended that maps label habitats and biotopes with potential (modelled and potentially 543 not occupied) and realised (delineated by direct observation) habitat labels or modifiers.

544 Improvements to the consistency of habitat classifications

545 The use of habitat classification involves accepting some of the inherent assumptions 546 associated with HCSs. An assumption common to all schemes is that all habitats can be 547 classified into distinct and identifiable classes. It is often the case that observations, collected 548 during habitat mapping surveys, fail to fall neatly into classes within a scheme. The presence 549 of ecotones and mosaics of heterogeneous habitat reduces the clarity of class membership, 550 and hence the ability to accurately reflect conditions on the seabed.

551 The difficulty in classifying a continuous variable into a discrete class is further complicated 552 when HCSs lack a quantitative definition, or clear 'decision rules' for each class. Also, as 553 habitat mapping became heavily based upon physical measurements in the past 15 years (e.g., 554 Al-Hamdani and Reker, 2007; Cameron and Askew, 2012, Vasquez et al., 2015, Galparsoro 555 et al., 2015), there came an increasing demand for quantitative definitions. Without this 556 information, qualitative classifications are often open to subjective interpretation and 557 inconsistencies between studies or adjoining maps. 
558 Common schemes, such as EUNIS and CMECS (Federal Geographic Data Committee,

559 2012), lack quantitative definitions that could define classes. For EUNIS, the absence of these

560 definitions is a result of it being constructed from several classification schemes, making it

561 difficult to achieve consensus on what those definitions should be. The large part of the

562 scheme that originated in Connor et al. (2004) was designed primarily as a biological

563 classification system, with the physical descriptions at the higher levels being convenient

564 groupings that did not necessarily need to adhere strictly to any definitions.

565 HELCOM HUB provides quantitative delineation and classification rules within each of the

566 classification levels. As an example, the system differentiates between soft and hard bottom

567 substrata (Level 3), by a spatial coverage percentage of hard substrates within a given area

568 (HELCOM, 2013). The latter also holds true for the delineation between infaunal and

569 epifaunal dominated biotopes (Level 4), and between epifaunal communities (Level 5) and

570 dominating species (Level 6).

571 Other HCSs also incorporate quantitative thresholds, for example, the Australian NISB

572 habitat classification also uses decision rules (such as quantitative measures, percentage cover

573 thresholds, and particle size bands) at all levels of the hierarchy and for the class modifiers.

574 The PHC scheme uses objective methods to calculate specific attributes, such as rugosity and

575 slope, to reduce subjective attribution and delineation, and clear thresholds that separate

576 classes e.g., depth ranges for megahabitats or particle size for substrata. However, some

577 attribute classes lack quantitative definitions which could lead to subjectivity, and hence

578 variation, during the manual delineation of features. The use of quantitative attribution will

579 also provide a more robust basis for: (i) initial classification of habitats; (ii) the estimation of

580 how well the observation fits the assigned class; and (iii) greater certainty about the detection

581 of change over time during repeat mapping. Quantitative thresholds and class definitions 
582 should not be specific to certain sampling devices or biased towards the survey techniques 583 that were used to initially define classes. Ideally, the class or biotope description should 584 include an indication of how the biotope may appear using a variety of survey techniques.

585

586

The influence of the structure of a classification scheme on a habitat map

587 HCSs designed for habitat mapping, and aligned to the types of information typically

588 collected, are likely to be easier to use, reduce subjectivity during the classification of seabed 589 information and generate more accurate maps. A single, nested hierarchical structure 590 probably generates the most consistent classification between studies, but typically provide 591 less breadth and flexibility during the classification process. It is recommended that rigid, 592 hierarchical systems need to have a good system for updating either their structure or 593 classified units as new delineations are required.

594 Modifiers are an extremely useful structural component for appending additional information 595 onto a class without necessarily complicating the production or display of habitat maps. For 596 example, modifiers could be used to represent: (i) observations on the condition of habitats; 597 (ii) evidence of anthropogenic pressures (e.g. litter, physical alteration); (iii) labels for 598 habitats that are hard to classify (e.g. fall between classes or units containing a mosaic of 599 classes); or (iv) associations with other biological features not covered by the HCS such as 600 large shoals of fish. To ensure their consistent application of modifiers, HSCs should once 601 again provide detail on when and how to apply modifiers.

\section{Contextual attribution of habitat codes within habitat classification schemes}

603 A scheme name or code for a habitat provides a unique and brief title for the classified 604 feature. Habitat classes are typically supported by a fuller description that many contain, for 605 example, the identity and relative abundance of characterising species as well as the 
606 prevailing physico-chemical conditions present. However, this supporting information is

607 typically detached from the map and just the class names are presented. It is recommended 608 that all HCSs be available on an online vocabulary server and that digital maps include a 609 unique resource identifier for each habitat class. Although essential, the name of a particular 610 habitat may not necessarily be the most informative or valuable attribution for a map feature.

611 It is likely that additional attribution providing details, for example, on class sensitivity, 612 rarity, or ecosystem services provided (e.g., Salomidi et al., 2012; Galparsoro et al., 2014) 613 may be of greater interest to the end user. It is also recommended that HCSs provide a 614 broader array of attribution with each class. This will make it easier for maps to display 615 alternative types of information as well as more contextual information for the class name.

\section{Providing multi-purpose marine habitat maps}

618 Habitat mapping is conducted for a multitude of purposes and this is reflected in the number 619 and variety of HCSs available. Classification schemes can be either specialised or generic. 620 Generic classifications are best suited for baseline data, inventory mapping and marine spatial 621 planning. Specialised classifications provide greater specificity, and therefore applicability, 622 for specific topics or management issues (e.g., climate change, fisheries, conservation).

623 Management outcomes are presumed to be more effective when based on specialised HCS 624 aligned to the topic of interest. Despite this, most mapping studies tend to produce just one 625 map, or set of maps, based on just one adopted HCS scheme. Based on the cost and effort 626 required to gather the data used for habitat mapping, the practice of producing just one map, 627 based on one HCS per study, is potentially inefficient and narrows greatly the breath of the 628 mapping exercise. Each use or purpose should be linked to the most informative and 629 appropriate classification scheme. It is therefore recommended that habitat mappers use 
630 several HCSs to generate multiple map products, each with a dedicated purpose. For

631 example, a suite of maps that offers the greatest utility might include, among others,: (i) a 632 generic, descriptive map for inventory purposes, (ii) a map attributed according to 633 representativity, rarity or conservation value for the protection of species and habitats (design 634 of Marine Protected Areas networks), (iii) sensitivity maps for supporting marine spatial 635 planning and management, (iv) a map of ecosystem services for regional valuations and 636 assessments, (v) maps of essential fish habitat for fisheries management, and (vi) 637 geomorphological and surficial sediment maps for sediment dynamics, extraction and mining.

638 The production of a suite of map products does not hamper our ability to standardise or 639 merge maps within a thematic area, nor does it necessarily represent a significant additional 640 workload for mappers. The ability of mappers to produce multiple maps, based on several 641 classification schemes, can be simplified if translation tables (tables that map classes of one 642 HCS to units of another HCS) are made available. It is therefore recommended that mappers 643 use multiple HCSs to produce a suite of maps and that this activity is supported by the 644 development of translation tables (e.g. JNCC, 2018).

\section{5}

\section{4. Conclusions}

647 Marine HCSs differ greatly within six key properties, due in part to their initially intended 648 application and structure (i.e. whether they follow a strictly hierarchical approach to 649 classification and how readily they incorporate modifiers for the incorporation of greater 650 detail). Consequently, each HCS has specific strengths and weaknesses. These strengths and 651 weaknesses, along with the inherent assumptions associated with the classification process, 652 modify the final representation of habitats when mapped. It is important for mappers to be 653 aware of how these properties and assumptions are transferred into marine habitat maps, and 


\begin{abstract}
654 whether these constrain their subsequent use for a wider variety of applications. Equally, 655 decisions on how mappers use HCSs within the mapping process, which is independent of the 656 properties associated with the HCS, also introduces additional artefacts and biases. Having 657 identified all of these issues, recommendations have been provided for improving HCSs for 658 marine mapping as well as enhanced working practices for mappers using these schemes. For 659 example, limiting interpretation of data to fit only one HSC compromises the information we 660 can communicate through our maps and limits their use to a wider range of stakeholders. It is 661 hoped that implementation of these recommendations will lead to: (i) greater certainty and 662 usage within mapping studies; (ii) more consistency between studies and adjoining maps; and 663 (iii) increased use of mapped products by a greater diversity of end users.
\end{abstract}

664

665 5. Acknowledgements:

666 Part of this work was supported by VAPEM project (Fisheries and Aquaculture Directorate 667 of the Basque Government). 
670 6. ICES format:

671 Pares, P., and Britain, B. 1965. Predator-prey behaviour of herring (Clupea harengus

672 albertus). International Journal of Applied Biology, 24: 132-135.

673 7. References

674 Al-Hamdani, Z., and Reker, J. 2007. Towards marine landscapes in the Baltic Sea ecoregion.

675 BALANCE Interim Report 117.

676 Allee, R.J., Dethier, M., Brown, D., Deegan, L., Ford, R. G., Hourigan, T.F., Maragos, J.,

677 Schoch, C., Sealey, K., Twilley, R., and Weinstein, M.P. 2000. Marine and estuarine 678 ecosystem and habitat classification.

679 Andersen, J.H., Manca, E., Agnesi, S., Al-Hamdani, Z., Lillis, H., Mo, G., Populus, J., Reker, 680 J., Tunesi, L. and Vasquez, M. 2018. European Broad-Scale Seabed Habitat Maps Support 681 Implementation of Ecosystem-Based Management. Open Journal of Ecology, 8, 86-103. 682 https://doi.org/10.4236/oje.2018.82007

683 Brown, C.J., Smith, S.J., Lawton, P., and Anderson, J.T. 2011. Benthic habitat mapping: A 684 review of progress towards improved understanding of the spatial ecology of the seafloor 685 using acoustic techniques. Estuarine, Coastal and Shelf Science, 92: 502-520.

686 Cameron, A., and Askew, N. (eds.). 2011. EUSeaMap - Preparatory Action for development 687 and assessment of a European broad-scale seabed habitat map. Final report. Available online 688 at www.emodnet-seabedhabitats.eu/outputs

689 Connor, D.W. ed. 1997. Classification of benthic marine biotopes of the north-east Atlantic. 690 Proceedings of the second BioMar-Life workshop, Dublin, 10 September 1995. Unpublished, 691 Joint Nature Conservation Committee.

692 Connor, D.W., Allen, J.H., Golding, N., Howell, K.L. Lieberknecht, L.M. Northen., K.O., 693 and Reker, J.B. 2004. The Marine Habitat Classification for Britain and Ireland Version 
694 04.05. Introductory Text. In: JNCC (2015). Marine Habitat Classification for Britain and 695 Ireland Version 15.03. ISBN 1861075618.

696 Council Directive 92/43/EEC of 21 May 1992 on the conservation of natural habitats and of 697 wild fauna and flora (Habitats Directive), OJ L206, 22.07.92.

698 Cowardin, L.M., Carter, V., Golet, F.C., and LaRoe, E.T. 1979. Classification of wetlands 699 and deepwater habitats of the United States. US Department of the Interior, US Fish and 700 Wildlife Service.

701 Davies, C.E., Moss, D., and Hill, M.O. 2004. EUNIS Habitat Classification Revised 2004. 702 Report to the European Environment Agency - European Topic Centre on Nature Protection 703 and Biodiversity October 2004. http://www.emodnet704 seabedhabitats.eu/PDF/GMHM4_EUNIS_2004_report.pdf

705 Dethier, M.N. 1992. Classifying marine and estuarine natural communities: An alternative to 706 the Cowardin system. Natural Areas Journal, 12: 90-98.

707 Directive 2008/56/EC of the European Parliament and of the Council of 17 June 2008 708 establishing a framework for community action in the field of marine environmental policy 709 (Marine Strategy Framework Directive) [2008] OJ L164/19.

710 EMODnet. 2016. EMODnet Thematic Lot $n^{\circ} 3$ Seabed Habitats EMODnet Phase 2 - Final 711 report. Reporting Period: 27/08/2013 - 30/09/2016. Available online at http://www.emodnet712 seabedhabitats.eu/outputs.

713 Finck, P., Heinze, S., Raths, U., Riecken, U., and Ssymank, A. 2017. Rote Liste der 714 gefährdeten Biotoptypen Deutschlands - dritte fortgeschriebene Fassung 2017. - Münster 715 (Landwirtschaftsverlag) - Naturschutz und Biologische Vielfalt. 156, 637 S. 
716 Galparsoro, I., A. Borja, M., and Uyarra, C. 2014. Mapping ecosystem services provided by

717 benthic habitats in the European North Atlantic Ocean. Frontiers in Marine Science, 1.

718 Galparsoro, I., Connor, D.W., Borja, A., Aish, A., Amorim, P., Bajjouk, T., Chambers, C., 719 Coggan, R., Dirberg, G., Ellwood, H., Evans, D., Goodin, K.L., Grehan, A., Haldin, J., 720 Howell, K., Jenkins, C., Michez, N., Mo, G., Buhl-Mortensen, P., Pearce, B., Populus, J., 721 Salomidi, M., Sánchez, F., Serrano, A., Shumchenia, E., Tempera., F., and Vasquez, M. 722 2012. Using EUNIS habitat classification for benthic mapping in European seas: Present 723 concerns and future needs. Marine Pollution Bulletin, 64: 2630-2638.

724 Galparsoro, I., Rodríguez, J.G., Menchaca, I., Quincoces, I., Garmendia, J., and Borja, Á. 725 2015. Benthic habitat mapping on the Basque continental shelf (SE Bay of Biscay) and its 726 application to the European Marine Strategy Framework Directive. Journal of Sea Research, $727 \quad 100: 70-76$.

728 Greene, H.G., Bizzarro, J.J., O’Connell, V.M., and Brylinsky, C.K. 2007. Construction of 729 digital potential marine benthic habitat maps using a coded classification scheme and its 730 application. Mapping the seafloor for habitat characterization: Geological Association of 731 Canada Special Paper, 47: 141-155.

732 Greene, H.G., Bizzarro, J.J., Tilden, J.E., Lopez, H.L., and Erdey, M.D. 2005. The benefits 733 and pitfalls of geographic information systems in marine benthic habitat mapping. Wright, 734 D.J., and Scholz, A.J., Place Matters: Geospatial Tools for Marine Science, Conservation, 735 and Management in the Pacific Northwest. Oregon State University Press, Corvallis, OR.

736 Greene, H.G., Yoklavich, M.M., Starr, R.M., O'Connell, V.M., Wakefield, W.W., Sullivan, 737 D.E., McRea, J.E., and Cailliet, G.M. 1999. A classification scheme for deep seafloor 738 habitats. Oceanologica acta, 22: 663-678. 
739 Guarinello, M.L., Shumchenia, E.J., and. King J.W. 2010. Marine habitat classification for

740 ecosystem-based management: a proposed hierarchical framework. Environmental

741 Management, 45: 793-806.

742 HELCOM. 1998. Red List of marine and coastal biotopes and biotopes complexes of the

743 Baltic Sea, Belt Sea and Kattegat. Baltic Sea Environment Proceedings No. 75.

744 HELCOM. 2013. HELCOM HUB - Technical Report on the HELCOM Underwater Biotope 745 and habitat classification. Baltic Sea Environment Proceedings No. 139.

746 HELCOM. 2015. BALSAM Project 2013-2015: Recommendations and Guidelines for

747 Benthic Habitat Monitoring with Method Descriptions for Two Methods for Monitoring of 748 Biotope and Habitat Extent.

749 Hilbert, D.W., Hughes, L., Johnson, J., Lough, J. M., Low, T., Pearson, R.G., Sutherst, R.W., 750 and Whittaker., S. 2007. Biodiversity conservation research in a changing climate, Australian 751 Government Department of the Environment and Water Resources: 72.

752 Huang, Z., Brooke, B. P., and Harris, P. T. 2011. A new approach to mapping marine benthic 753 habitats using physical environmental data. Continental Shelf Research, 31: S4-S16.

754 Mount, R., Bricher P., and Newton, J. 2007. National Intertidal/Subtidal Benthic (NISB) 755 Habitat Classification Scheme. Hobart, Australia: Australian Greenhouse Office; National 756 Land \& Water Resources Audit; School of Geography and Environmental Studies, University 757 of Tasmania.

758 Reiss, H., Birchenough, S., Borja, A., Buhl-Mortensen, L., Craeymeersch, J., Dannheim, J., 759 Darr, A., Galparsoro, I., Gogina, M., Neumann, H., Populus, J., Rengstorf, A. M., Valle, M., 760 van Hoey, G., Zettler, M. L., and Degraer. S. 2014. Benthos distribution modelling and its 761 relevance for marine ecosystem management. ICES Journal of Marine Science. 
762 Parry, M.E.V. 2014. JNCC Marine Habitat Classification for Britain and Ireland: Overview 763 of User Issues. JNCC Report No. 529. Available online at: http://jncc.defra.gov.uk/page-6757

764 Populus J., Vasquez M., Albrecht J., Manca E., Agnesi S., Al Hamdani Z., Andersen J., 765 Annunziatellis A., Bekkby T., Bruschi A., Doncheva V., Drakopoulou V., Duncan G., 766 Inghilesi R., Kyriakidou C., Lalli F., Lillis H., Mo G., Muresan M., Salomidi M., Sakellariou 767 D., Simboura M., Teaca A., Tezcan D., Todorova V. and Tunesi L. 2017. EUSeaMap, a 768 European broad-scale seabed habitat map. 174p. http://doi.org/10.13155/49975

769 Robinson, C.L.K., and Levings, C.D. 1995. An overview of habitat classification systems, 770 ecological models, and geographic information systems applied to shallow foreshore marine 771 habitats. Canadian Manuscript Report of Fisheries and Aquatic Sciences 2322. Department of 772 Fisheries and Oceans Science Branch, British Columbia, Canada. pp 65.

773 Salomidi, M., Katsanevakis, S., Borja, A., Braeckman, U., Damalas, D., Galparsoro, I., 774 Mifsud, R., Mirto, S., Pascual, M., Pipitone, C., Rabaut, M., Todorova, V., Vassilopoulou, 775 V., and Vega Fernández, T. 2012. Assessment of goods and services, vulnerability, and 776 conservation status of European seabed biotopes: a stepping stone towards ecosystem-based 777 marine spatial management. Mediterranean Marine Science, 13: 49-88.

778 Schiele, K., Darr, A., Zettler, M. L., Friedland, R., Tauber, F., von Weber, M., and Voss, J. 779 2015. Biotope map of the German Baltic Sea. Marine pollution bulletin, 96: 127-135.

780 Schiele, K., Darr, A., and Zettler, M.L. 2014. Verifying a biotope classification using benthic 781 communities - an analysis towards the implementation of the European Marine Strategy 782 Framework Directive. Marine Pollution Bulletin, 78: 181-189.

783 Sherman, K., and Alexander L. M. (eds). 1986. Variability and management of Large Marine 784 Ecosystems. American Association for the Advancement of Science (AAAS) Selected 785 Symposium 99, Westview Press, Boulder, CO, pp 319. 
786 Valentine, P.C., Todd, B.J. and Kostylev, V.E. 2005. Classification of Marine Sublittoral

787 Habitats, with Application to the Northeastern North America. American Fisheries Society 788 Symposium 41:183-200.

789 Vietti, R.C., Harris, C.M., Susanna, M.G., Iampietro, P., Kvitek, R., Greene, H.G., Chiantore, 790 M., Giuliani, S., and Giorgi, F. 2001. Terra Nova Bay Antarctica Special Protection Area 791 (ASP number 161), bathymetry, habitat interpretation and community distribution map: 792 Istituto Idrografico della Marine, Programma Nazionale di Ricerche in Antartide, Officine 793 Grafiche Novara 1091 S.P.A., Genoa, Italy.

794 Vasquez, M., Mata Chacón, D., Tempera, F., O'Keeffe, E., Galparsoro, I., Sanz Alonso, J.L., 795 Gonçalves, J.M.S., Bentes, L., Amorim, P., Henriques, V., McGrath, F., Monteiro, P., 796 Mendes, B., Freitas, R., Martins, R., and Populus, J. 2015. Broad-scale mapping of seafloor 797 habitats in the north-east Atlantic using existing environmental data. Journal of Sea Research, 798 100: 120-132.

799 Yoklavich, M.M., Greene, H.G., Cailliet, G.M., Sullivan, D.E., Lea, R.N. and Love, M.S., 800 2000. Habitat associations of deep-water rockfishes in a submarine canyon: an example of a 801 natural refuge. Fishery Bulletin - National Oceanic and Atmospheric Administration, 98: $802 \quad 625-641$.

803 Zacharias, M.A., and Roff, J.C. 2000. A hierarchical ecological approach to conserving 804 marine biodiversity. Conservation Biology, 14: 1327-1334. 805 806 
Table 1. Marine (benthic) habitat classification schemes used to document the variation in the six scheme properties considered.

\begin{tabular}{|c|c|c|}
\hline Habitat Classification Scheme & Description & $\begin{array}{l}\text { Examples of } \\
\text { usage }\end{array}$ \\
\hline $\begin{array}{l}\text { European Nature Information System } \\
\text { (EUNIS) - Davies et al. (2004) } \\
\text { http://eunis.eea.europa.eu/ }\end{array}$ & $\begin{array}{l}\text { EUNIS is a pan-European habitat classification scheme developed between } \\
1996 \text { and } 2001 \text { by the European Environment Agency (EEA) (Davies et al., } \\
\text { 2004). It considers both marine and terrestrial habitats in Europe. The } \\
\text { geographical scope of the EUNIS marine scheme is the marine waters off the } \\
\text { European mainland, including offshore islands (British Isles, Cyprus, Iceland, } \\
\text { but not Greenland), and the archipelagos of the European Union Member States } \\
\text { (Canary Islands, Madeira, and the Azores). EUNIS marine scheme covers the } \\
\text { entire seabed from the intertidal zone to the abyss, and also includes a section of } \\
\text { pelagic habitats. In the marine sector, it is based on the Joint Nature } \\
\text { Conservation Committee (JNCC) Marine Habitat Classification for Britain and } \\
\text { Ireland (Connor et al., 2004) and habitat types developed by the Barcelona and } \\
\text { Helcom marine conventions (Barcelona Convention, 1998; Helsinki } \\
\text { Commission, 1998). }\end{array}$ & $\begin{array}{l}\text { EUNIS supports } \\
\text { inventory mapping } \\
\text { (EMODnet), } \\
\text { ecosystem-based } \\
\text { management } \\
\text { (Andersen et al., } \\
\text { 2018) and policy } \\
\text { implementation } \\
\text { Marine Strategy } \\
\text { Framework } \\
\text { Directive (Council } \\
\text { Directive } \\
\text { 2008/56/EC). }\end{array}$ \\
\hline $\begin{array}{l}\text { HELCOM Underwater Biotope and } \\
\text { Habitat classification system } \\
\text { (HELCOM HUB) - HELCOM } \\
\text { (2013) http://www.helcom.fi/baltic- } \\
\text { sea-trends/biodiversity/helcom-hub }\end{array}$ & $\begin{array}{l}\text { HELCOM HUB was developed to be a comprehensive classification system for } \\
\text { marine biotopes of the Baltic Sea (HELCOM, 2013). Its origins go back to the } \\
\text { HELCOM EC-NATURE Red List Project (HELCOM, 1998) which was a first } \\
\text { Baltic Sea wide classification scheme based on substrate type and bathymetry. } \\
\text { Its classification rules mainly relied on expert judgment and biological } \\
\text { classification criteria were not included. In 2007, the goal was set to renew the } \\
\text { Red List Classification system by a HELCOM Red List Biotope Expert Group. } \\
\text { Previous attempts had been made to apply EUNIS to the Baltic Sea region but } \\
\text { the system was recognized to poorly represent its biotic and abiotic } \\
\text { characteristics (Galparsoro et al., 2012). Nevertheless, HELCOM HUB was to } \\
\text { be compatible with EUNIS and account for available biological information on }\end{array}$ & $\begin{array}{l}\text { Supports the } \\
\text { national } \\
\text { implementation of } \\
\text { the Marine } \\
\text { Strategy } \\
\text { Framework } \\
\text { Directive (Council } \\
\text { Directive } \\
\text { 2008/56/EC). }\end{array}$ \\
\hline
\end{tabular}




\begin{tabular}{|c|c|c|}
\hline & $\begin{array}{l}\text { marine biotopes from the Baltic Sea. HELCOM HUB is primarily focused on } \\
\text { benthic habitats/biotopes - the pelagic environment is only dealt with in the } \\
\text { upper part of the classification system. As one major improvement, HELCOM } \\
\text { HUB provides clear quantitative classification rules for both abiotic and } \\
\text { biological criteria. It was therefore used as a basis for the development of the } \\
\text { national classification system of the German Red List of Threatened Habitat } \\
\text { Types for both the North and the Baltic Sea (Finck et al. 2017). }\end{array}$ & \\
\hline $\begin{array}{l}\text { Potential Habitat Characterization } \\
\text { Scheme (PHCS) - Greene et al. } \\
(1999,2005,2007)\end{array}$ & $\begin{array}{l}\text { This classification covers deep-water habitats within North America and has } \\
\text { been expanded to include shallow water habitats, arctic to tropical regions, } \\
\text { including Antarctica (Vietti et al., 2001) and estuaries (Greene et al., 2007b). } \\
\text { This scheme has been specifically developed for seafloor mapping and uses } \\
\text { common mapping information such as multibeam echosounder data, video, } \\
\text { photographs taken with still cameras and seafloor samples from grabs. The } \\
\text { attributions used to classify the seafloor are mainly based on physical } \\
\text { parameters and features and therefore, has a 'bottom-up' structure. The } \\
\text { classification scheme is unusual in that it recognises four spatial scales. The first } \\
\text { three scales can be defined with acoustic methods whereas the finest scale } \\
\text { habitats can only be delineated with direct observation (via video, photographic } \\
\text { still imagery, diver observations or seafloor sampling) Greene et al. (2005, } \\
\text { 2007). }\end{array}$ & $\begin{array}{l}\text { Fisheries } \\
\text { management } \\
\text { (Greene et al., } \\
2005,2007 \text { ) }\end{array}$ \\
\hline $\begin{array}{l}\text { Hierarchical Framework of Marine } \\
\text { Habitat Classification for Ecosystem- } \\
\text { Based Management (HFMHC) - } \\
\text { Guarinello et al. (2010) }\end{array}$ & $\begin{array}{l}\text { This classification framework is specifically designed for promoting ecosystem- } \\
\text { based management. The upper levels of the scheme start with the global } \\
\text { classification of large marine ecosystems. Subsequent levels include } \\
\text { recognizable ecosystem units; e.g. estuary, and broad, geological formations } \\
\text { such as drowned river valley. The flexibility to add user-defined classes at the } \\
\text { lower levels of all three strands means the framework can be applied in any } \\
\text { geographic location and is not limited by the methods used to observe any of the } \\
\text { three strands. The framework incorporates the central concepts of ecosystem- }\end{array}$ & $\begin{array}{l}\text { Ecosystem-based } \\
\text { management } \\
\text { (Guarinello et al., } \\
\text { 2010) }\end{array}$ \\
\hline
\end{tabular}




\begin{tabular}{|c|c|c|}
\hline & $\begin{array}{l}\text { based management within the structure of the framework. This ensures that the } \\
\text { products of this HCS reflect the values and objectives of ecosystem-based } \\
\text { management. }\end{array}$ & \\
\hline $\begin{array}{l}\text { Classification of Sublittoral Habitats } \\
\text { (CSH) - Valentine et al. (2005) }\end{array}$ & $\begin{array}{l}\text { This classification scheme was designed to describe and classify habitats in } \\
\text { terms of geological, biological and oceanographic attributes. It is unusual in that } \\
\text { the scheme also captures information on the effects of natural and anthropogenic } \\
\text { processes on habitats. The purpose of the classification is to provide a } \\
\text { foundation for scientific research and environmental management of seafloor } \\
\text { habitats across a relatively large, regional area. Although initially developed for } \\
\text { the Gulf of Maine region (an area that reaches depths of approximately } 400 \mathrm{~m} \\
\text { but also has submarine canyon heads that incise the continental shelf and reach } \\
\text { depths of up to } 800 \mathrm{~m} \text { ), the scheme is a generic classification and can therefore } \\
\text { by applied to any continental shelf and shelf basin environment globally } \\
\text { (excluding some low-latitude environments). }\end{array}$ & $\begin{array}{l}\text { Fisheries } \\
\text { management } \\
\text { (Valentine et al., } \\
\text { 2005) }\end{array}$ \\
\hline $\begin{array}{l}\text { Australian National } \\
\text { Intertidal/Subtidal Benthic Habitat } \\
\text { Classification Scheme (NISB) } \\
\text { http://lwa.gov.au/products/pn21267 }\end{array}$ & $\begin{array}{l}\text { The NISB scheme was developed to identify a "uniform definition of } \\
\text { communities, habitats and ecosystems" at both state and national scales, and } \\
\text { spatial information that is informative for assessing critical climate change } \\
\text { issues and the detecting change or loss of habitats or communities. The } \\
\text { proposed scheme covers all of Australia's territorial waters between the high } \\
\text { tide and the approximate outer limit of the photic zone (depth of } 50-70 \mathrm{~m} \text { ). }\end{array}$ & $\begin{array}{l}\text { Inventory mapping } \\
\text { of ecoregions } \\
\text { (bioregional } \\
\text { subregions) }\end{array}$ \\
\hline $\begin{array}{l}\text { Coastal and Marine Ecological } \\
\text { Classification Standard (CMECS) - } \\
\text { Madden et al. }(2005) \\
\text { https://www.cmecscatalog.org/cmecs/ }\end{array}$ & $\begin{array}{l}\text { CMECS was developed by the National Oceanic and Atmospheric } \\
\text { Administration (NOAA) and NatureServe. The scheme is founded on existing } \\
\text { schemes (e.g. Cowardin et al. (1979), Dethier (1992), Greene et al. (1999), } \\
\text { Allee et al. (2000), Zacharias and Roff (2000) and Connor (2004)). CMECS } \\
\text { includes all estuarine, coastal and marine waters under U.S. jurisdiction in North } \\
\text { America. This includes wetlands, the intertidal zone, coastal and deep-water } \\
\text { habitats (including the Great Lakes) as well as the pelagic realm. }\end{array}$ & $\begin{array}{l}\text { Inventory mapping } \\
\text { (Madden et al., } \\
\text { 2005) }\end{array}$ \\
\hline
\end{tabular}

